\title{
Social Support Structures; A catalyst to Sustainable Adolescents' Reproductive Health Programming in Ghana
}

\author{
Stephen L. ${ }^{1}$, Mbugua J. ${ }^{1}$, Kyalo N. D. ${ }^{1} \&$ Maitho T. ${ }^{1}$ \\ ${ }^{1}$ Open Distance and eLearning Campus, University of Nairobi, Nairobi, Kenya \\ Correspondence: Stephen L., Open Distance and eLearning Campus, University of Nairobi, P.O. Box 30197-100, \\ Nairobi, Kenya. E-mail: stephen2016.uk@gmail.com; mbugua04@yahoo.com
}

Received: November 10, 2019

Accepted: December 12, 2019

Online Published: May 26, 2021

doi:10.5539/jsd.v14n4p1

URL: https://doi.org/10.5539/jsd.v14n4p1

\begin{abstract}
The issue of adolescents' reproductive ill-health has been widely recognized as a multi-scalar social problem that affects various sectors in the world today. In this regard, this empirical study was conducted to establish the extent to which social support structures, contribute to sustainable implementation of adolescents' reproductive health programme in the Brong Ahafo Region of Ghana. A descriptive cross-sectional survey and correlational designs, underpinned by the pragmatic paradigm or mixed-method research as the appropriate research technique, was adopted study to investigate its purpose and objectives. Through a multistage sampling technique, a sample size of 189 respondents was generated from a target population of 332 stakeholders, with data obtained through key informant interview schedules, focus group discussions and direct observation, and structured and unstructured questionnaires administered in Ghana. It was found that social support structures and sustainable implementation of adolescent's reproductive health programme are positively and significantly linked, since the model results shows that $\mathrm{r}=0.831 . \mathrm{R}^{2}=0.691, \mathrm{~F}(1.180)=401.713 . \mathrm{p}<0.001<0.05$. We concluded that for sustainable implementation of adolescent's reproductive health programmes, social support structures play a significant role in the process. Hence programme implementers and duty bearers of adolescent's reproductive health interventions should take note of this fact and act accordingly.
\end{abstract}

Keywords: adolescent's; support structures; sustainable reproductive health; social stress;

\section{Introduction}

It has been recognized recently that the absence of clearly-defined functioning social welfare practices and systems is one of the greatest threats of the world's progress particularly developing countries (Sheafor and Horejsi, 2008). The fact that many families, individuals and social organizations in developing countries depends on social safety networks, such as extended family lineage property and neighbourhoods support for safety, security and livelihoods, exacerbates this great challenge and its widespread enormous socio-economic development implications. In many developing countries like Ghana, Social Work practice is a helping profession that provides services aimed at assisting societies function better for their vulnerable population. It is designed to support people burdened with varying degrees of social problems to function better within society (Segal et al., 2010). Segal et al, further contended several professions-including the health care professionals who strive to save lives through health conditions, police officers who are entrusted with the protection and safety of society and legal professionals that contribute to protecting people's civil rights-provide this human-centred services with the aim improving conditions and social functioning. Implying that meaningful and sustainable development cannot take place in societies afflicted with a host of social problems without meaningful interventions, hence the need to establish the institutions with requisite capacity in terms of logistics, skills, collaborative efforts, to promote comprehensive social services including reproductive healthcare counselling. Social support structures are the most important safety nets that influence the well-being and quality of life of all people (Muna, Hadidi, and Jamal, 2014; Jessica \& Hamid 2015).

Yet, the quest for rapid social change in less developed countries like Ghana is associated with technological, economic and political changes, at the expends of human and social repercussions of the forces of modernization (Rwomire, 2012). Rwomire further contends that social and economic resources are crucial for the attainment of national development because development is both material and social. Economic growth and improved productivity, and social relates to qualitative changes in the lives of people, attitudes, institutions and relationships 
(Rwomire, 2012). Much as Ghana has benefitted from modernization, its negative consequences include issues relating to child protection safety nets, rural-urban drift, physical and mental disability, conjugal violence and care of the elderly. In Ghana, for example, adolescents' suicide reflects the reality of the phenomenon, yet there is lack of studies with official statistics on adolescent suicide in Ghana (Emmanuel, Joseph, Charity \& Jennifer,2015; Haas, Schaefer, \& Kornienko, 2010). In Ghana however, the concept of social support system, is relatively developing hence faces unique challenges between professional principles and traditional family methods.

The Ghanaian society like most developing societies is beset with a host of social problems that require professional social work intervention to ensure a coordinated effort (Baffoe M. and Dako-Gyeke, M. 2013). These circumstances have tended to promote a breakdown of social welfare systems in the country, which has given rise to streetism involving 300,000 adolescents live and work on the street, suicides and other social vices (DOSW, 2019). According to Ghana's 2010 population and housing census report (GSS, 2013), 6467 deaths were recorded among the young person's representing $35 \%$ of all deaths categorized under deaths by accident, violence, homicide, or suicide.

Recognizing the consequences of the situation in 2010, a pilot Ghana's Adolescent Health and Development Programme, dubbed " Ghana Adolescent's Reproductive Health (GHARH)" was launched to combat existing deteriorated adolescents' health conditions in Ghana- in the Brong Ahafo Region- which was funded by DFID, UK Government, with the aim and objective to upscale appropriate ARH care, and to also improve access to and utilization of appropriate reproductive health services, through collaborative, supportive and coordinated stakeholder environment. The focus was to ensure effective implementation through participatory and decentralized approaches in the delivery of ARH facilities.

The fact that there still exist a multitude of social problems, as discussed before constitutes a particular course of concern. Its implications and impact on sustainable development cannot be overemphasized because human beings occupied an important part of the ecosystems of society. The ability to create and solve problems enhances the functioning of people and contributes greatly to society's development. If societies do not have strong and sustainable social support structures to solve their social problems, development cannot be sustained for improved quality of life for their citizens. For the reason that all nations need both social and economic resources to achieve national development, the role of social workers in facilitating the process of development through enabling individuals and societies to reach out for each other via a mutual need for self-fulfillment is crucial (Rwomire, 2012).

Against this background, this study thus sets out to conduct a situational analysis on the extent to which social support structures, influence sustainable adolescent's reproductive health programme in the Brong Ahafo Region of Ghana. Against which it was hypothesized that Social support structures have no significant influence on pathways to sustainable adolescent's reproductive health programme in the Brong Ahafo Region of Ghana.

\section{Literature Review}

In this study, social support structures are analyzed in two major forms including the structural support, otherwise refers to the availability of potential support-givers, and then functional support also refers to the perception of support. However, in both scenarios, this study sought to establish what other studies have to say about the functional capacity, in terms of institutional logistics, staff requisite skills and institutional collaboration of support intuitions (social welfare and community development, police service, human right offices, Adolescents Reproductive Health caregivers, as mentioned in the previous chapter), who are often mandated to manage social stress in society. This current study believes that proper support interventions can often affect operations of the structural support, for example, through peer groups, which may have a stronger correlation with the health of adolescents.

A review of empirical literature indicated that researchers have provided an extensive overview of the different models explaining the effects of social support on health. Appropriate infrastructure is a critical component of supportive structures for better adolescents' health care delivery. Decker, Ahorlu, Pfeiffer Brigit (2015) found that through considerable efforts and investments in proper resources in the United States, the rate of adolescent pregnancy and complications significantly decreased (57\% declined) over the past two decades as opposed large geographical and socioeconomic disparities in the developing countries, where rural adolescents are more likely to give birth than teens in urban areas, as are young black females as compared to white females. Six key strategies and programmatic efforts including; seeking a better understanding of the complexity of adolescent lifestyle; expand the frontiers of quality sexual health education; active youth engagements through efficient technology and media; enhance access to sexual health service; create tailored interventions; and above all create a supportive policy environment, were identified by the study to help address the challenge of adolescent pregnancies. 
Similarly, UNFPA (2017) argued that adolescents have unique, fundamental needs related to their health and wellbeing. Such studies indicate challenges, as well as the critical role of logistics, play in the development, strengthening, and promotion of the health and sexual well-being of all adolescents. Socially support organizations were helpful during puberty means that adolescents' needs efficiently managed their emotional challenges, good hygiene, access to adequate sanitation and disposal mechanisms, were remarkable.

Other evidence shows that social linkages or institutional networks are necessary components of social support infrastructure. Barker (2007) argued that despite the considerable interest among programmes on the theme of adolescent help-seeking and the need to promote it, much work is needed to arrive at a consensus about the dimension, promotion and measurement procedure of help-seeking through the positive use of both informal and formal sources of support. The importance of caring and meaningful relationships, as well as pro-social connections with individuals and social institutions for promoting healthy and positive developmental outcomes, have been confirmed by various consultations and studies (WHO 2014b). Barker further contended that several youth programmes exist in the community but the youth participation is in them is woefully inadequate due to low awareness of existing programmes. It was rather found that youth involvement in informal groups is higher than structured youth programmes. In total, more than $38 \%$ of young people surveyed, it was found that about $40 \%$ had used informal social support in the community, as a strategy to manage stresses. This study will seek to establish innovative, collaborative, context-sensitive and systemic project management approaches to social support structures for improved community-level sustainable adolescents' healthcare interventions.

On the contrary, Franklin Glozah, (2015), indicated that there is presently no internationally agreed sets of indicators for assessing the role of social support systems or structures on adolescent health and wellbeing. Mr. Glozah concluded that the family, friends, and school could play a crucial role in the psychosocial context of the health and wellbeing of adolescents. This means that social support systems may be indispensable in helping adolescents cope with stressors, or protecting them from psychological distress, even though these studies failed to establish capacity and requisite skills of support institutions. Similarly, in studies conducted by UNICEF, (2016), it further noted that child malnutrition and neglect, corporal punishment, domestic violence, sexual abuse or violence, and exploitation are relevant international development issues that cause routine stresses to the most vulnerable youthful population of the world today. These revelations were established through semi-structured interviews, involving males and female adolescents from developing countries. Specific findings showed that health and wellbeing adolescents were largely designed for the rich population. The study findings suggest that effective communication, mutual respect, and support from significant others, in the midst of stressful life events, contribute substantially to a holistic construction and meaning of health and wellbeing by Ghanaian adolescents. Hence, effective social support structures could serve as intervening sources in the situation.

However, on the matters of adequate support for support systems, Thoits, (1986), stated that almost no attention has been paid to social relationships, networks, and supports structures, as well as their consequences for adolescents' health needs. Further, Shamagonam, Pedro, John, Beery, Catherine, Skosana and Moretlwe (2018) made a statement on three basic aspects of social relationships, which are often referred to as social support, which were clearly distinguished into (l) their existence or quantity (i.e., social integration), (2) their formal structure (i.e., social networks), and (3) their functional or behavioural content (i.e., the most precise meaning of "social support") and the causal relationships between the structure of social relationships (social integration and networks) and their functional content (social support) must be more clearly understood. It means that intermediate-level social structures such as groups, families, and communities also have important consequences for social integration, networks, and supports. Even though these studies explored how functional social support systems may influence the health and wellbeing of adolescents, their functionality was measured in terms of technical logistics, financial, and personnel capacity. They could not well as demonstrate how institutional integration and networking could create a better moderating effect on social stress management between participatory project management and GARH sustainability.

On the contrary, Leme, Prette, and Coimbra (2015) maintained that there is no consensus in the literature concerning the effects of family set-up on the psychological well-being of adolescents, as compared with social skills. The study evaluated the perception of adolescents on the influence of family configuration, social skills, and social support appraisals as a potential determinant of adolescent psychological well-being in Europe. A total of 454 adolescents aged between 13 and 17 years emanating from nuclear, separated and remarried family backgrounds and drawn from public high schools participated in the survey. It was concluded that social skills of empathy, self-control, civility, social resourcefulness, and effective systems and skills, including social support appraisals from friends and family, were the best predictors of adolescent psychological well-being.

Social protection systems are expected to be sufficiently measured based on different traditions, cultures, and 
values of the beneficiaries. These are the benchmarks of efficiency. That explains the extent to which literature is divided on the influence of social support structures and programme or project sustainability. Some authorities argue that social support structures have little effect on programme sustainability, while others argued on the contrary. As a result, adolescents are prone to negative peers, and risky health behaviours (UNICEF, 2016). In Ghana, adolescent girls experience a higher degree of social isolation than boys are due to school drop-out, early marriage, depression, suicides and a range of other factors (Osafo, 2018). Social isolation implies an increase in the risk of sexual violence, HIV, and unplanned pregnancy in the country.

From the above studies reviewed, it is visible that most of the studies adopted a qualitative methodology that was scientifically challenged in terms of representative views, and above all, were also silent on the influence of support structures to project sustainability. Effective implementation of ARH interventions may not only need both technical and organizational aspects but also mixed methods to establish social support structures that influence the sustainability of development programs, especially adolescent reproductive health intervention. A good social support institution must have the knowledge and technical skills for implementation but it must also have the appropriate organizational structure, network, and relationship with other institutions to foster collaboration (Fikree, 2017). By implication, more research and theory are needed on the determinants of social integration, networks, and support as well as their consequences for stress and health.

\section{Methodology}

A pragmatist paradigm guided a mixed research approaches were employed to obtain relevant data by this study. A cross-sectional survey design approach in which data was collected from a research questionnaire conceived on the basis of a typical project life cycle (PLC). This approach allowed the use of the PLC as the logical framework for the examination of project management principles adopted for the implementation of the GHARH project in Ghana.

Mixed research approaches have been deemed appropriate and the best description of the research phenomenon through both natural and social settings of critical investigation (Creswell, 2012). The study also adopted a descriptive survey and correlational research design have been used to study the social and scientific phenomenon that exists in participatory project management processes, social support structures and sustainability of adolescent reproductive health programme

The sample population of the study was based on 189 project stakeholders in Ghana. The sample size cut across the entire spectrum of secondary and primary stakeholders such as the top management executives of adolescents' health clubs, District and National Directors of Health, Education, and Officers of National Youth Authority, Population Council, Representatives of the Municipal and District Assemblies, and District Level Social Support Structures including; Social Welfare Officers, the District DOVSU Officers, Adolescents Reproductive Health Caregivers and the District CHRAJ Offices. Others include the national directors of Ghana, the Local Government Service, who were also treated as the unit of analysis in the study, and constituting a target population of 359 participants. A sample size of 189 was therefore determined to represent the entire population by the application of Yamane (1967), sample size determination research formula as follows.

$$
\mathrm{n}=\frac{\mathrm{N}}{1+\mathrm{N}\left(\mathrm{e}^{2}\right)}=359 / 1+359\left(0.05^{2}\right)=189.189
$$

A five (5)-section questionnaire was designed and administered to each respondent. The programme examined in the study area was the Ghana Adolescent's Reproductive Health Progarame. The data obtained was analyzed to established descriptive information and inferential statistics. Pearson correlation coefficient and regression analysis identified the relationship between the independent variable (participatory project initiation process) and the dependent variable (sustainable implementation of Ghana ARH programme). The amount of variance in the sustainable management of Ghana ARH programme accounted for by participatory project initiation process, was obtained through regression analysis.

\section{Data Collection, Analysis, Interpretation and Presentation}

This section presents data analysis, presentation, interpretation and discussion of the findings, based on the objectives of the paper. Prior to the analysis the research data, the research responds rate was computed, where 189 sampled size changed to 182 respondents. Data collected the rough questionnaires, interviews, Focus Group Discussions, P ersonal Observations and document analysis on the variables was comprehensively analyzed to establish degree of association and inferential statistics. 


\subsection{Background Information of Respondents}

The socio-demographic and social characteristics of the respondents are presented in Table1. From the table, it is evident that about 45 percent and 56 percent of the study respondents were males and females respectively. Also, about 1, 44, and 54 percent of the research population were made up of national and district level caregivers and official respectively. The demographic analysis of the data indicates that a majority (35.7\%) of the respondents were found between 30-39 years, while about 51 percent of the entire respondents were certificate holders. Although these variables were not part of the major variables of the study, building information on them serves as a vital complement for making a factual judgment regarding the underpinning variables of the study. It puts the study on better ground to making an informed qualitative analysis of the views, opinions, and expressions by the respondents.

Table 1. Background information of respondents

\begin{tabular}{lll}
\hline Respondents Profile & Frequency & Percent \\
\hline Gender & 81 & 44.5 \\
Female & 101 & 55.5 \\
Male & $\mathbf{1 8 2}$ & $\mathbf{1 0 0 . 0}$ \\
Total & & \\
Institutional Designation & 2 & 1.1 \\
National officials & 2 & 1.1 \\
Regional officials & 98 & 53.8 \\
District officials & 80 & 44.0 \\
Caregivers & $\mathbf{1 8 2}$ & $\mathbf{1 0 0 . 0}$ \\
Total & & \\
Age Cohort & 22 & 12.1 \\
10-19 yrs & 51 & 28.0 \\
$20-29$ yrs & 65 & 35.7 \\
$30-39$ yrs & 44 & 24.2 \\
40 yrs + & $\mathbf{1 8 2}$ & $\mathbf{1 0 0 . 0}$ \\
Total &
\end{tabular}

\subsection{Descriptive analysis of data}

This aspect of the study contained a descriptive analysis of the moderating variable. Thus, data were collected to establish the effects of social support systems, such as the department of social welfare and community development in the delivery process of Adolescents Reproductive Health initiatives. With this mindset, the respondents were asked to rate some item statements using a 5 point Likert scale ranging from $1=$ strongly disagree (SD), 2=Disagree (D), 3=Neutral (N) 4=Agree (A) and 5=Strongly Agree (SA), on the extent to which institutional capacity (technical and logistics) and institutional collaboration of social support structures (SSS) towards sustainable community-level Adolescents Reproductive Health programming. Table 2 presents descriptive results. 
Table 2. Descriptive analysis

\begin{tabular}{|c|c|c|c|c|c|c|c|c|}
\hline \multirow[t]{3}{*}{$\mathbf{S} / \mathbf{N}$} & & SD & $\mathbf{D}$ & $\mathbf{N}$ & $\mathbf{A}$ & SA & Mean & Std. Dev. \\
\hline & \multirow[t]{2}{*}{ Item Statements } & $\mathbf{F}$ & $\mathbf{F}$ & $\mathbf{F}$ & $\mathbf{F}$ & \multicolumn{3}{|l|}{$\mathbf{F}$} \\
\hline & & $(\%)$ & $(\%)$ & $(\%)$ & $(\%)$ & $(\%)$ & & \\
\hline $\mathbf{A}$ & \multicolumn{8}{|l|}{ Institutional Access } \\
\hline $\mathrm{A1}$ & $\begin{array}{l}\text { I agree there is adequate access to } \\
\text { support institutions }\end{array}$ & $\begin{array}{l}3 \\
(1.6)\end{array}$ & $\begin{array}{l}154 \\
(84.6)\end{array}$ & $\begin{array}{l}28 \\
(15.4)\end{array}$ & $\begin{array}{l}0 \\
0.0\end{array}$ & $\begin{array}{l}1 \\
0.5\end{array}$ & 2.154 & 0.362 \\
\hline $\mathrm{A} 2$ & $\begin{array}{l}\text { Poor coverage of institutional support } \\
\text { influences social support service seeking }\end{array}$ & $\begin{array}{l}0 \\
0.0\end{array}$ & $\begin{array}{l}19 \\
(10.4)\end{array}$ & $\begin{array}{l}48 \\
(26.4)\end{array}$ & $\begin{array}{l}65 \\
(35.7)\end{array}$ & $\begin{array}{l}50 \\
(27.5)\end{array}$ & 3.802 & 0.96 \\
\hline $\mathrm{A} 3$ & $\begin{array}{l}\text { Challenges affect access to service SSS } \\
\text { platforms }\end{array}$ & $\begin{array}{l}1 \\
(0.5)\end{array}$ & $\begin{array}{l}30 \\
(16.5)\end{array}$ & $\begin{array}{l}23 \\
(12.6)\end{array}$ & $\begin{array}{l}32 \\
(17.6)\end{array}$ & $\begin{array}{l}96 \\
(52.7)\end{array}$ & 4.06 & 1.157 \\
\hline A4 & $\begin{array}{l}\text { Supplenmentary learning on reproductive } \\
\text { health issues is affected by acess to SSS. }\end{array}$ & $\begin{array}{l}3 \\
(1.6)\end{array}$ & $\begin{array}{l}32 \\
(17.6)\end{array}$ & $\begin{array}{l}32 \\
(17.6)\end{array}$ & $\begin{array}{l}57 \\
(31.3)\end{array}$ & $\begin{array}{l}58 \\
(31.9)\end{array}$ & 3.758 & 1.101 \\
\hline A5 & $\begin{array}{l}\text { There is adequate public knowledge on the } \\
\text { social mandate of SSS }\end{array}$ & $\begin{array}{l}10 \\
(5.5)\end{array}$ & $\begin{array}{l}172 \\
(94.5)\end{array}$ & & $\begin{array}{l}0 \\
0.0\end{array}$ & $\begin{array}{l}0 \\
0.0\end{array}$ & 1.945 & 0.229 \\
\hline \multicolumn{2}{|c|}{$\underline{\text { Semi-composite Index }}$} & & & & & & \multirow[t]{2}{*}{3.144} & \multirow[t]{2}{*}{0.762} \\
\hline B & \multicolumn{6}{|l|}{ Institutional capacity } & & \\
\hline$\overline{\mathrm{B} 1}$ & $\begin{array}{l}\text { The educational level of staff' is affect } \\
\text { continue seeking of social support }\end{array}$ & $\begin{array}{l}0 \\
0.0\end{array}$ & $\begin{array}{l}0 \\
0.0\end{array}$ & $\begin{array}{l}0 \\
0.0\end{array}$ & $\begin{array}{l}168 \\
(92.3)\end{array}$ & $\begin{array}{l}14 \\
(7.7)\end{array}$ & 4.077 & 0.267 \\
\hline B2 & $\begin{array}{l}\text { I do agree that requisite skills of social } \\
\text { workers are good }\end{array}$ & $\begin{array}{l}32 \\
(17.6)\end{array}$ & $\begin{array}{l}125 \\
(68.7)\end{array}$ & $\begin{array}{l}16 \\
(8.8)\end{array}$ & $\begin{array}{l}9 \\
(4.9)\end{array}$ & $\begin{array}{l}0 \\
0.0\end{array}$ & 2.011 & 0.681 \\
\hline B3 & $\begin{array}{l}\text { That institutional transport capacity is } \\
\text { affects effective service delivery }\end{array}$ & $\begin{array}{l}3 \\
(1.6)\end{array}$ & $\begin{array}{l}89 \\
(48.9)\end{array}$ & $\begin{array}{l}87 \\
(47.8)\end{array}$ & $\begin{array}{l}2 \\
(1.1)\end{array}$ & $\begin{array}{l}1 \\
(0.5)\end{array}$ & 4.489 & 0.501 \\
\hline B4 & $\begin{array}{l}\text { Inadequate residential accommodation is an } \\
\text { issue to SSS operations }\end{array}$ & $\begin{array}{l}2 \\
(1.1)\end{array}$ & $\begin{array}{l}13 \\
(7.1)\end{array}$ & $\begin{array}{l}165 \\
(90.7)\end{array}$ & $\begin{array}{l}1 \\
0.5\end{array}$ & $\begin{array}{l}1 \\
0.5\end{array}$ & 3.071 & 0.258 \\
\hline B5 & $\begin{array}{l}\text { Adequate financial support is a critical issue } \\
\text { for SSS smooth operations }\end{array}$ & $\begin{array}{l}5 \\
2.7\end{array}$ & $\begin{array}{l}1 \\
0.5\end{array}$ & $\begin{array}{l}0 \\
0.0\end{array}$ & $\begin{array}{l}113 \\
(62.1)\end{array}$ & $\begin{array}{l}63 \\
(34.6)\end{array}$ & 4.346 & 0.477 \\
\hline Ser & ii-composite Mean \& Std. Dev & & & & & & 3.599 & 0.437 \\
\hline C In & stitutional Collaboration & & & & & & & \\
\hline $\mathrm{C} 1$ & $\begin{array}{l}\text { That SSS joint collaboration on social } \\
\text { service affects reproductive health } \\
\text { seeking in the area. }\end{array}$ & $\begin{array}{l}2 \\
(1.1)\end{array}$ & $\begin{array}{l}4 \\
(2.2)\end{array}$ & $\begin{array}{l}6 \\
(3.3)\end{array}$ & $\begin{array}{l}169 \\
(92.9)\end{array}$ & $\begin{array}{l}1 \\
0.5\end{array}$ & 3.901 & 0.395 \\
\hline $\mathrm{C} 2$ & $\begin{array}{l}\text { There are constraints in visible joint } \\
\text { social network platforms (group } \\
\text { WhatsApp) }\end{array}$ & $\begin{array}{l}0 \\
0.0\end{array}$ & $\begin{array}{l}0 \\
0.0\end{array}$ & $\begin{array}{l}0 \\
0.0\end{array}$ & $\begin{array}{l}125 \\
(68.7)\end{array}$ & $\begin{array}{l}57 \\
(31.3)\end{array}$ & 4.313 & 0.465 \\
\hline $\mathrm{C} 3$ & $\begin{array}{l}\text { That SSS do not have integrated social } \\
\text { welfare action plans reflecting } \\
\text { reproductive health needs. }\end{array}$ & $\begin{array}{l}3 \\
1.6\end{array}$ & $\begin{array}{l}1 \\
0.5\end{array}$ & $\begin{array}{l}23 \\
(12.6)\end{array}$ & $\begin{array}{l}87 \\
(47.8)\end{array}$ & $\begin{array}{l}68 \\
(37.4)\end{array}$ & 4.225 & 0.688 \\
\hline $\mathrm{C} 4$ & $\begin{array}{l}\text { That SSS are constrain with joint social } \\
\text { welfare supervisory schemes }\end{array}$ & $\begin{array}{l}2 \\
1.1\end{array}$ & $\begin{array}{l}8 \\
(4.4)\end{array}$ & $\begin{array}{l}30 \\
(16.5)\end{array}$ & $\begin{array}{l}69 \\
(37.9)\end{array}$ & $\begin{array}{l}73 \\
(40.1)\end{array}$ & 3.956 & 0.468 \\
\hline $\mathrm{C} 5$ & $\begin{array}{l}\text { That there is limited joint collaboration } \\
\text { on youth reproductive health service. }\end{array}$ & $\begin{array}{l}5 \\
2.7\end{array}$ & $\begin{array}{l}6 \\
(3.3)\end{array}$ & $\begin{array}{l}29 \\
(15.9)\end{array}$ & $\begin{array}{l}69 \\
(37.9)\end{array}$ & $\begin{array}{l}73 \\
(40.1)\end{array}$ & 4.126 & 0.88 \\
\hline$\underline{\text { Sem }}$ & I-composite Mean \& Std. Dev & & & & & & 4.104 & 0.579 \\
\hline Ove & all Composite Mean \& SD & & & & & & 3.616 & 0.593 \\
\hline
\end{tabular}




\section{Results}

Results in Table 2 indicate the frequencies percentages, means, as well as the standard deviations of various responses recorded during the study on the sub-items of the variable social support structures. The data was collected and analyzed with an aim to established from the respondents perspective on how social support structures and its major indicators (institutional access, Institutional capacity, and institutional collaboration) influence the sustainable implementation of adolescent's reproductive health programme.

\subsection{Evidence of Social Support Structures Access and Functionality in the Study Area}

\subsubsection{Institutional Access}

The results in Table, 2 presents information on the institutional access. The analysis for example shows that about $84 \%$ of the respondent's disagree that access to support institutions is adequate, about $35 \%$ and $27 \%$ agree and strongly agree respectively that the existing coverage of coverage of support institutions is poor in influencing service seeking. On public knowledge on the mandate of social support systems about $95 \%$ disagree of having adequate knowledge on those institutions. The mean raged between 2.154 and 3.144 with a standard deviation of less $<1$ for all the items except on item number A3 and A4 which were 1.157 and 1.101 respectively. Averagely, institutional access had a sub-composite mean of 3.144 and an SD of 0.762. This shows that in the opinion of majority of the respondent's institutional access has an influence on sustainable implementation of the reproductive health programme in Ghana.

\subsubsection{Institutional Capacity}

The results in Table 2 further shows that out of the 182 respondents, about $92 \%$ of them agree that the educational qualification of staff of the social support structures affect continue support seeking. While about $18 \%$ and $69 \%$ respectively strongly disagree and disagree that the workers of social support structures have the requisite skills to transmit social change. Also, about $62 \%$ and $35 \%$ of the respondent respectively agree and strongly agreed that financial support is a critical issue in the operations of social support structures. The mean ranges between 2.011 to 4.346 , with a variance of $<1$ for the line items, indicating that the views were converging on the indicator. On the average institutional capacity had a sub-composite mean of 3.599 and an SD of 0.437 , indicating that institutional capacity has an influence on sustainable implementation of the reproductive health programme in Ghana.

\subsubsection{Institutional Collaboration}

On the issue of institutional collaboration, the result further that about $92 \%, 69 \%, 48 \%, 40 \%$, and $41 \%$ of the respondenents respectively agree, and strongly agree that, joint institutional collaboration, social network plaform constraints, absence of an integrated social action plans, and limited joint collaboration are critical issues confronting the support institutions. Further, the mean ranges between 3.901 to 4.313 , with a variance of $<1$ for the line items, which indicates that the views and opinions of the responds hard converged on the indicator. Averagely, institutional collaboration had a sub-composite mean of 4.104 and an SD of 0.579, which suggest that majority of the respondents agree that institutional collaboration has an influence on sustainable implementation of the reproductive health programme in Ghana.

However, the overall analysis indicates that the composite mean of social support structures was 3.616, while the standard deviation was 0.593 , which was an indication that on the average, the respondents had agreed that social support structures is critical issue in matters of adolescent's reproductive health. Also, the composite standard deviation $<1$, gave the indication that, a lot of the responses were evenly spread around the variable mean.

The results further show that the most dominant indicator was an institutional collaboration, where a sub-composite mead of 4.104 and a standard deviation of 0.579 was recorded respectively. It was followed by the indicator of Institutional capacity $(\mathrm{M}=3.599$ and $\mathrm{SD}=0.437)$. While institutional access as an indicator resulted in $(\mathrm{M}=3.144$, and $\mathrm{SD}=0.762$ ), which also indicated an average agreement by the respondents. This implies that social support structures in the opinion of the majority respondents, influences the sustainable implementation of adolescents reproductive health programme in the study area.

\subsection{Evidence of Influence of Social Support Structures on Sustainable Implementation of Adolescents Reproductive} Health programme in the Study Area

\subsubsection{Correlation Analysis}

Before testing the hypothesis on the variable, a correlation analysis was conducted in order to establish the degree of association between social support structures and sustainable implementation of adolescent's reproductive health programme. The results is presented in Table 3. 
Table 3. Correlation analysis of social support structures and sustainable implementation of ARH programme

\begin{tabular}{|c|c|c|c|c|c|}
\hline & & $\begin{array}{l}\text { Institutional } \\
\text { Capacity }\end{array}$ & $\begin{array}{l}\text { Requisite staff } \\
\text { social response } \\
\text { skills }\end{array}$ & $\begin{array}{l}\text { Institutional } \\
\text { Collaboration }\end{array}$ & $\begin{array}{l}\text { Social } \\
\text { support } \\
\text { structures }\end{array}$ \\
\hline Sustainable & Pearson & 0.651 & 0.715 & 0.838 & 0.831 \\
\hline Implementation & Correlation & & & & \\
\hline \multirow[t]{2}{*}{ GHARH programme } & $\begin{array}{l}\text { Sig. } \\
\text { tailed })\end{array}$ & .007 & .013 & .019 & .013 \\
\hline & $\mathrm{N}$ & 182 & 182 & 182 & 182 \\
\hline
\end{tabular}

Based on the results presented in Table 3, the study discovered that there is significantly strong positive correlation $(r=0.831)$ between social support structures and the sustainable implementation of adolescent's reproductive health programme in the study area. The results also revealed a positively strong and statistically significant association between all the indicators of this independent variable and the dependent variable, since all the 2-tailed significance values are less than 0.05 at $95 \%$ level of confidence. This implies that increases or decreases in one variable do significantly relate to increases or decreases in the other. The correlation of these two variables also identified that some of the main indicators (the independent variable) between them are more correlated than each other. In this regards this study has previously identified the purposes of low correlation and suggested some of the improvement actions from the previous related literatures and interview findings to make the social support structures more effective to improve the sustainability of reproductive health initiative.

\subsubsection{Simple Regression Results}

Since the correlation results could not determine causality, this study further conducted simple regression analysis to establish the causal relationship between social support structures and the sustainable implementation of adolescent's reproductive health programme in the study area. Table 4 contains the result of the simple regression analysis based on the hypothesized that: Social Support Structures do not significantly influence the sustainable implementation of the adolescent's reproductive health (ARH) programme in the study area of Ghana.

Regression Model: In this model, sustainable implementation of adolescent's reproductive health programme in Ghana (dependent variable) was regressed against social support structures (independent variables).

The model equation employed for the testing of the hypothesis was:

$$
\mathrm{Y}=\mathrm{ao}+\beta_{1} X_{1}+\varepsilon
$$

Where;

$\mathrm{Y}=$ Sustainable implementation of adolescent's reproductive health programme, $\boldsymbol{X}_{\mathbf{1}}=$ Social Support Structures, ao $=$ Constant, $\boldsymbol{\beta}_{\mathbf{1}}=$ Coefficient of regression, $\boldsymbol{\varepsilon}=$ error margin. $\mathrm{Y}=0.974+0.831 \mathrm{X} 6$ (based on the information in Table 4). The result of the regression analysis is presented in Tables 4 based on the objective of study and its stated hypothesisre.

Table 4. Regression analysis

Model Summary

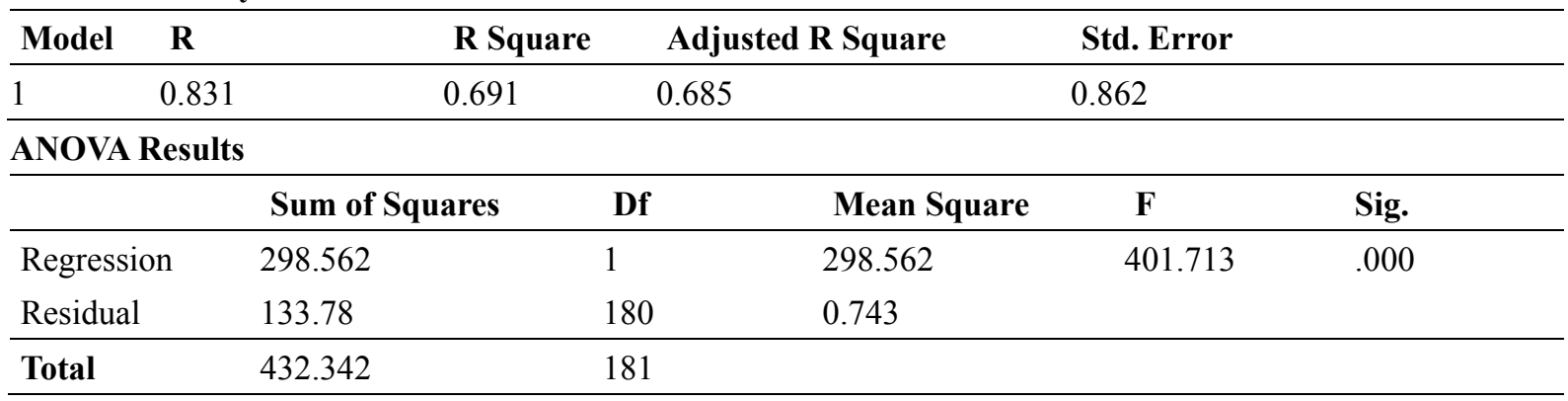




\section{Regression Coefficients}

\begin{tabular}{llllll}
\hline & \multicolumn{2}{l}{$\begin{array}{l}\text { Unstandardized } \\
\text { Coefficients }\end{array}$} & $\begin{array}{l}\text { Standardized } \\
\text { Coefficients }\end{array}$ & & \\
& B & Std. Error & Beta & t & Sig. \\
\hline (Constant) & 0.974 & 0.189 & & 4.624 & .000 \\
Social Support Structures & 0.876 & 0.104 & 0.831 & 6.500 & .000 \\
\hline
\end{tabular}

The results in Table 4 presents the overall result for social support structures and its indicators. First of all, the $\mathrm{R}$ square in Table 4 defines the percentage of the dependent variable variation as explained by a given model, since the $r$-squared is a coefficient of determination. The results show that social support structures had a significant positive effect on sustainable implementation of adolescent's reproductive health programme, F statistic (401.713 at $\mathrm{p}<0.05), \mathrm{R}^{2}=0.691$. The finding that $\mathrm{R}^{2}=0.691$, implies that about $69 \%$ of variation in the sustainable implementation of adolescent's reproductive health programme in the study area is explained is explained by variation on social support structures. $\mathrm{R}^{2}=0.691$, means that social support structures contributed to about $69 \%$ of the sustainable implementation of adolescent's reproductive health programme, implies that $31 \%$ of the changes in the sustainable implementation of adolescent's reproductive health programme in the study area could not be explained by the model but rather can be attributed to other factors or conditions in the environment.

It was further established from the results that the influence of the social support structures was significant since 0.000 (p-value) $<0.05$. Therefore, the null hypothesis was rejected with a conclusion that there was a significant relationship between Social Support Structures and sustainable implementation of adolescent's reproductive health programme in the study area.

The regression model further provided statistical control through which the study also established the influence of Social Support Structures. That is holding the independent variable at zero will result in a positive influence of 0.974 on the sustainable implementation adolescent's reproductive health programme in the study area. A unit change in Social Support Structures will result in 0.831 increments in the sustainable implementation of adolescent's reproductive health programme in the study area. The results show that there is a positive causal relationship between social support structures and the pathways to a sustainable adolescent reproductive health programme in the Brong Ahafo Region, Ghana.

The quantitative findings have been confirmed by qualitative information gathered from in-depth studies; openedended questions, and interviews with key informants. For instance, during an interactive session with key informants it indicated by majority of them that even though proper recognition has not usually been given to the social support systems in the implementation of such social intervention programmes, support institutions have an enormous role to successful implementation and programming of community-level adolescents' reproductive health initiatives. Further, majority of the support structure officials indicated there were still alarming cases of adolescents issues of pregnancies, STIs, leading to school dropout among adolescent girls, which they blamed on the lack of coordinated efforts between existing public agencies to deal with complicated issues. They noted that the implementation of adolescent's reproductive health programme in the study area intervention came with a narrow framework that reduces effective stakeholder engagement of support systems and institutions. In justifying this one participant from the department of social welfare noted that;

"Even though my department is mandated to championed the issues of adolescent's welfare, we were not integrated into the programme. So our enormous experiences were not included in building a proper exit planned for the programme. I think the community entry adopted for the programme was not the best, in the programme isolated core stakeholders at the level of the most crucial decision".

When asked about the skills and logistical capacity of social support structures; the majority of the interviewees, indicated that they have limited human resources challenges as compared with institutional operational logistics; funds, transport, and accommodation. On the part of requisite skills, the participants indicated they only need periodic refresher courses to bring them to speed with current issues of adolescent's socio-economic needs. A participant noted that;

"Due to poor funding and operational logistics, as well as acute lack of means of transport the support institutions in this country are not often able to achieve the mandates, .......we hear vulnerable people suffer in communities every day because they can't be 
reached, ......the central government subvention does not come as expected. As a result, institutions cannot collaborate on joint actions to address popular needs".

These qualitative revelations further imply that support was confronted by varying development issues in their quest to discharge their mandates on the social development needs of the Ghanaian society. Such issues constitute very useful lessons for adolescents' reproductive health care delivery, initiations, planning and implementation, and sustainable efforts. This evidence signifies that sustainable programming and implementation of adolescent's reproductive health interventions need to consider that well-established social support structures are important to achieve the sustainable programming.

\section{Discussions}

The descriptive analysis showed that institutional access had a mean score of 3.144, Institutional capacity had a mean of 3.599. Intuitional collaboration had a mean of 4.316. The results of the data revealed that $\mathrm{r}=0.831 . \mathrm{R}^{2}$ $=0.691, \mathrm{~F}(1.180)=401.713 . \mathrm{p}<0.001<0.05$. This evidence suggests that the more efficient the social support structures, the higher the chances of sustainable implementation of adolesecent's reproductive health programmes in Ghana.

These findings were found to be consistent and mutual with the key findings of James et al. (2018), who established in an assessment of services specifically addressing sexual, reproductive and mental health that, almost $50 \%$ all adolescents have limited access to psycho-social and physical related healthcare; as management of adolescents' presenting complaints and their comprehensive management including psycho-social status and risk profile, due to poor availability of support systems in developing countries. However, unlike this study James et al. (2018), could not further explore the capacity of support institutions in terms of their influence on the sustainability of ARH initiatives.

The results indicated that appropriate social support infrastructure is a critical component for better adolescents' health care delivery. It revealed that, with rightful availability of well-resourced local level support structures, the greater chance of better welfare for the adolescents. On this note WHO (2014) found that through considerable efforts and investments in proper resources in the United States, the rate of adolescent pregnancy and complications significantly decreased (57\% declined) over the past two decades as opposed large geographical and socioeconomic disparities in the developing countries, where rural adolescents are more likely to give birth than teens in urban areas, as are young black females as compared to white females. Six key strategies and programmatic efforts were identified by the study to help address the challenge of adolescent pregnancies. They include seeking a better understanding of the complexity of adolescent lifestyle; expand the frontiers of quality sexual health education; active youth engagements through efficient technology and media; enhance access to sexual health service; create tailored interventions; and above all create a supportive policy environment. This indicates both challenges and the critical role of logistics in the development, strengthening, and promotion of the health and sexual well-being of all adolescents. Also, WHO (2015). argued that adolescents have unique, fundamental needs related to their health and wellbeing. As a result, they socially support and organizational care during puberty means that adolescents need to be prepared and assisted to manage their emotional challenges aside from good hygiene, access to adequate sanitation and disposal mechanisms.

Other evidence shows that social linkages or institutional networks are necessary components of social support infrastructure. Barker (2007) argued that despite the considerable interest among programmes on the theme of adolescent help-seeking and the need to promote it, much work is needed to arrive at a consensus about the dimension, promotion and measurement procedure of help-seeking through the positive use of both informal and formal sources of support. The importance of caring and meaningful relationships, as well as pro-social connections with individuals and social institutions for promoting healthy and positive developmental outcomes, have been confirmed by various consultations and studies (WHO 2014). It was rather found that youth involvement in informal groups is higher than structured youth programmes. In total, more than $38 \%$ of young people surveyed, it was found that about $40 \%$ had used informal social support in the community, as a strategy to manage stresses. This study will seek to establish innovative, collaborative, context-sensitive and systemic project management approaches to social support structures for improved community-level sustainable adolescents' healthcare interventions. These findings, therefore, provide several useful ideas on the roles of support structures in youth health care programming.

\section{Conclusion and Recommendation}

The results of this study revealed that sustainable implementation of an adolescent reproductive health programme in the area is sensetive to social support structures and that support structures do have an influence on the sustainable programming and implementation of adolesecent's reproductive health interventions. The study 
demonstrated that indicators including institutional access, requisite institutional capacity in terms of staff skills and logistics, and institutional collaboration are very critical indicators that present a mix of influence where institutional collaboration was the dominant indicator, institutional capacity, and then institutional access, on the sustainable implementation of adolescent reproductive health programme in Ghana.

Therefore, in pursuing long-term sustainability of the ARH programming, the paper put forward the following recommendation with an objective of enhancing research knowledge and professional conducts. First, a policy framework to strengthen the capacity of social support structures and also sensitize the citizenry on the importance of support systems in managing psycho-social health needs of adolescents is required. Policymakers need to come up with policies to guide on how social support structures will be integrated into Adolescents Reproductive Health interventions should be implemented, by creating a systematic framework to boost the quality of projects outcomes. Secondly, the study established the importance of support systems or infrastructure on the sustainable implementation of Adolescent's Reproductive Health (ARH) programmes in Ghana. It then implies by extension that the project managers should ensure that projects managers for such projects need to engage in a broad base consultation to identify necessary social support structures during and at all stages of projects planning and execution, as well as post-implementation managements. Finally, this study was procured through the application of both descriptive survey and correlational research designs. These robust designs have ensured the paper to carry out deeper studies on both social and scientific phenomena, which are worth emulating or replicating elsewhere.

\section{Acknowledgements}

The authors of this study are much grateful for the support and cooperation received from the project implementors, as well as the project stakeholders and implementing patters of the Ghana Adolescents Reproductive Health programme, during and after the study. In fact their meaningful information provided during the research is commendable.

\section{References}

Aimee, B. S., Delany, K. M., \& Brahmbhatt, H. (2018). Social Support and Its Effects on Adolescent Sexual RiskTaking: A Look at Vulnerable Populations in Baltimore and Johannesburg. Journal of Adolescent Health.

Baffoe, M., \& Dako-Gyeke, M. (2013). Social problems and social work in Ghana: Implications for sustainable development. International Journal of Development and Sustainability, 2(1), 347-363.

Collins, K, A., Constanze, P., \& Brigit. (2015). ObristSocio-cultural and economic factors influencing adolescents' resilience against the threat of teenage pregnancy: a cross-sectional survey in Accra, Ghana

Crase, S. J., Hockaday, C., \& Cooper, M. P. (2007). Brief report: Perceptions of positive and negative support: Do they differ for pregnant/parenting adolescents and no pregnant, no parenting adolescents? Journal of Adolescence Reproductive Health, 30(3), 505-512. https://doi.org/10.1016/j.adolescence.2006.11.007

Creswell, J. W. (2012). Research design: Oualitative, quantitative, and mixed methods approach (2nd ed.). Thousand

Department of Social Welfare (DSW). (2019). Dealing with Streetism in Ghana.

Emmanuel, N.-B. Q., Joseph, O., Charity, S. A., \& Jennifer, P. (2015). Adolescent suicide in Ghana: A content analysis of media reports. International Journal of Qualitative Studies on Health and Well-being, 10(1). https://doi.org/10.3402/qhw.v10.27682

Fikree, M. (2017). The programmatic area on adolescent and vouth sexual and reproductive health (AYSRH) within MEASURE Evaluation's Family Planning and Reproductive Health Indicators Database.

Franklin, N. G. (2015). Exploring Ghanaian adolescents' meaning of health and wellbeing: A psychosocial perspective International Journal of Qualitative Studies on Health and Well-being; Regent University College of Science and Technology, Accra, Ghana, and University of Essex, Colchester, UK

Ghana Statistical Service (GSS). (2013). 2010 population \& housing census report: Children, adolescents and young people in Ghana. Accra.

Haas, S. A., Schaefer, D. R., \& Kornienko, O. (2010). Health and the Structure of Adolescent Social Networks. Journal of Health and Social Behavior, 51(4), 424-439. https://doi.org/10.1177/0022146510386791

Jessica, L. M., \& Hamid, R. (2015). Adolescent sexual and reproductive health: The global challenges. International Federation of Gynecology and Obstetrics, London, UK.

Joseph Osafo - Clinical Psychologist. (2018). Lack of Social Support System Major Cause of Suicides in Ghana. Annual Progress Ghana Health Services 
Leahy-Warren, P., McCarthy, G., \& Corcoran, P. (2012). First-time mothers: Social support, maternal parental selfefficacy and postnatal depression. Journal of Clinical Nursing, 21(3-4), 388-397. https://doi.org/10.1111/j.1365-2702.2011.03701.x

Leme, V. B. R., Del Prette, Z. A. P., \& Coimbra, S. (2015). Social Skills, Social Support and Well-Being in Adolescents of Different Family Configurations. Retrieved from www.scielo.br/paideia

Muna, S. H., \&Jamal, M. A. K. (2014). A Comparison of Social Support among Adolescents with and Without Visual Impairments in Jordan: A Case Study from the Arab Region. Journal of Visual Impairment \& Blindness.

Rwomire, A. (2012). The role of social work in national development. Social Work and Society, 10(1).

Segal, E. A., Gerdes, K. E., \& Steiner, S. (2010). An Introduction to the profession of social work: Becoming a change agent, Brook/Cole, Belmont, CA.

Shamagonam, J., Pedro, T. P., John, I., Moira, P. B., Catherine, M., Catherine, S., \& Sinead, D.-M. (2018). Assessment of adolescent and youth-friendly services in primary healthcare facilities in two provinces in South Africa. BMC Health Services Research, 18, 809. https://doi.org/10.1186/s12913-018-3623-7

Sheafor, B.W., \& Horeisi, C. R. (2008). Techniques and guidelines for social work practice. Allyn and Bacon, Boston.

Singh, S., \& Darroch, J. E. (2012). Adding it up: costs and benefits of contraceptive service. Estimates for New York: Guttmacher Institute and UNFPA. Retrieved from http://www.guttmacher.org/pubs/AIU-2012estimates.pdf

Thoits, P. A. (1986). Social support as coping assistance. Journal of Consulting and Clinical. https://doi.org/10.1037/0022-006X.54.4.416

UNFPA. (2017). Adolescent Sexual and Report Health. Retrieved Mav 1. 2018, from www.unfpa.org/resources/adolescent-sexual-and-reproduction

UNICEF. (2016). Application of a Human Rights Based Approach and a Gender Mainstreaming Strategy to Programming for Work with Adolescents in Latin America and the Caribbean. Regional Office for Latin America and the Caribbean: UNICEF.

WHO. (2014). Health for the world's adolescents: a second chance in the second decade: summary, World Health Organization. Retrieved July 28, 2016, from http://www.who.int/maternal_child_adolescent/topics/adolescence/seconddecade/en/

World Health Organization. (2014). Adolescent pregnancy: adolescence is a time of opportunity during which a range of actions can be taken to set the stage for healthy adulthood: fact sheet. Geneva.

World Health Organization. (2015). A standards-driven approach to improve the quality of health-care services for adolescents. Geneva: WHO.

Yamane, T., \& Row, S. (1960). Statistics: An Introductory Analysis (2nd ed.). New Jersey.

\section{Copyrights}

Copyright for this article is retained by the author(s), with first publication rights granted to the journal.

This is an open-access article distributed under the terms and conditions of the Creative Commons Attribution license (http://creativecommons.org/licenses/by/4.0/). 